\title{
Richard Quinn
}

\section{"A Great Poet, A Great American": Reading A Poet's Prose*}

In a 1985 article recounting his travels through China, Allen Ginsberg posits a question central to both Chinese Communism and American Democracy: "How much of the hyper-organization is really a support system for keeping the whole society together, and how much is a control system to keep power at the top." The 500 pages of essays, articles, blurbs, and letters comprising Deliberate Prose provide the most comprehensive account to date of Ginsberg's lifelong struggle against systems of control. Long before postmodern critiques of white, male, heterosexual master narratives, Ginsberg attacked those very narratives and the bureaucratic systems they support for unjustly circumscribing human experience and seeking to impose what he calls a "mechanical consciousness" on "the wild and beautiful America."

Yet, as Deliberate Prose also indicates, it would be a mistake to label Ginsberg a postmodern artist. "Poetry," he writes, "is the record of individual insights into the secret soul of the individual and because all individuals are one in the eyes of their creator, into the soul of the world." Those who believe that, on the contrary, our understanding of "the world" is merely a product of language games, where words like "natural," "universal," and "soul" reflect a misguided desire for purity beyond human speech and meddling, would undoubtedly find much in Deliberate Prose hopelessly naïve.

Edited by Bill Morgan with a foreword by Ed Sanders, the book, rather than plotting Ginsberg's thought chronologically, or dividing the work into formal generic categories, adopts a thematic approach. It opens with "Politics and Prophecies," beginning with the oft reprinted "Poetry, Violence, and the Trembling Lambs" (1959) and ending with "An Indirect Encounter: India" (1964), a brief critique of India's inability to care for its poorest citizens. Much of the work here and throughout the text has been published previously, though mostly in relatively obscure magazines, books, and pamphlets. If this opening section seems the most compelling, it is largely because of its passionate illustration of one citizen's outrage at our government's inability to

\footnotetext{
* Ginsberg, Allen. Deliberate Prose: Selected Essays 1952-1995. New York: HarperCollins, 2000.
} 
achieve our greatest ideals. "What ignorant hypocrisy," he asks in a piece on government infiltration of the underground press, "has so reversed conventional usage that now citizenly Thoreauvian pacifism (i.e. nonviolent antinuclear action) has been called 'terrorism' and actual government-inspired bombings, beatings, thievings and lies have been excused by the President of the U.S. as patriotic action . . . ?" Similarly, in an acceptance speech for the National Book Award in Poetry ("The Fall of America Wins an Award" [1974]) delivered by Peter Orlovsky, Ginsberg argues that the phrase "defense of a free world" is really "an aggressive hypocrisy that has damaged the very planet's chance of survival."

As becomes evident in later sections of the book, including "Drug Culture," "Mindfulness and Spirituality," and "Censorship and Sex Laws," Ginsberg's concern over government-sponsored oppression has much to do with his belief in the repressed potential of human consciousness. In one of the book's most wonderfully absurd pieces, originally published in none other than the Congressional Record, Ginsberg articulates the value of LSD to a subcommittee of the Senate Judiciary Committee (1966). He calls upon the committee to recognize how our freedom has been "caught up in a bureaucratic machine which is not built to serve some of our deepest personal feelings. A machine which closes down our senses, reduces our language and thoughts to uniformity, reduces our sources of inspiration . . . and doesn't really satisfy our deeper needs for communication with each other." Drawing on anecdotal evidence, Ginsberg describes the "new sense of openness, and lessening of prejudice and hostility to new experience" created in those who have taken the drug. These experiences, he continues, have led the new generation "to push for an environment less rigid, mechanical, [and] less dominated by Cold War habits." Yet Ginsberg realizes that personal anecdotes are not enough to convince Senators to overturn drug laws, so he concludes his testimony with a detailed report of misinformation concerning the health effects of LSD and calls for further scientific research into the drug.

Prophetic of government drug mania, Ginsberg was equally prophetic of the media's ability to set normative standards and manipulate public taste. Television "monopolizes our attention with secondhand imagery [and] packaged news" making it more difficult to explore the depths of selfhood through idiosyncratic activity. Presently, Ginsberg contends, because "systems of mass communication can communicate only officially acceptable levels of reality, no one can know the extent of the secret unconscious life." As mergers lead 
to increased consolidation, a process picking up speed over the last few years, Ginsberg's perceptions on media culture will continue to haunt us.

The last five sections of Deliberate Prose address subjects we expect of Ginsberg: literary technique, the Beat Generation, other writers and artists, and himself. Much to be gleaned from these fascinating texts is addressed more extensively in the many biographies of Beat writers, books of academic scholarship, and Ginsberg's other prose collections, particularly Allen Verbatim: Lectures on Poetry, Politics, Consciousness (1974) and Composed on the Tongue: Literary Conversations 1967-1977 (1980). In the acknowledgements for Deliberate Prose, Bill Morgan explains that he chose not to include pieces from Ginsberg's other published works and generally rejected interviews, journal entries, and correspondence. He did, however, include pieces like "Notes Written on Finally Recording Howl" and "Meditation and Poetics" which have been widely distributed.

One of the more tender moments in a section entitled "Autobiographical Fragments" is Ginsberg's "Confrontation with Louis Ginsberg's Poems" (1969). In this piece, Ginsberg addresses yet another system of control, poetic tradition. He cites Williams Carlos Williams who once told Ginsberg upon reading some of his imperfectly written traditional iambic verse, "In this mode perfection is basic." The advice stuck with Ginsberg, who found himself in an imperfect world, contributing to his rejection of standard verse forms in favor of a "new tradition" coming out of Whitman through Williams and anchored in his Beat friends like Jack Kerouac and Gregory Corso. This tradition, Ginsberg writes, is "one of improvised prosodies echoing our actual speech" rather than that of his "own father writing the outworn verse of previous century voices." Nevertheless, he found in his father's work a "sufficient condensation of idea, freedom of fancy, phrase modernity, depth of death-vision, and clarity of particular contemporary attention to transform the old 'lyric' form from an inverted fantasy to the deepest actualization of his peaceful mortal voice." Such an assessment indicates how arrival at one's personal voice is Ginsberg's mark of perfection while also suggesting that poetic traditions were better made than found.

Yet Ginsberg and his Beat brethren did not invent new traditions in a vacuum, and many pieces in Deliberate Prose explore Ginsberg's myriad influences. One source was the music of Charlie Parker and other jazz musicians. Ginsberg heard the protracted horizontal patterns of a musician like Lester Young as "breath units" and sought to recreate them as poetic lines. "My 
breath is long," Ginsberg explains in "Notes Written on Finally Recording Howl," "that's the Measure, one physical and mental inspiration of thought contained in the elastic of a breath." This breath unit, like "long saxophone chorus lines," became Ginsberg's poetic building block, not only in Howl, but in other major works like Kaddish and The Fall of America. As he explains in "How Kaddish Happened," the possibility of failure in improvised music, when musicians move away from what they know, detaching themselves from the harmonic or melodic grounding beneath, illustrates that "defeat" might finally lead to the one victory that matters. "Defeat like that is good for poetry," he writes, "you go so far out you don't know what you're doing, you lose touch with what's been done before by anyone, you wind up creating a new poetry-universe."

"When the Mode of the Music Changes, the Walls of the City Shake" included in a section entitled "Literary Technique and the Beat Generation" expresses these ideas most succinctly: "The only pattern of value or interest in poetry is the solitary, individual pattern peculiar to the poet's moment and the poem discovered in the mind and in the process of writing it out on the page." Thus writing is less about manipulating than about searching, less about control than about freedom, and at this point Ginsberg's politics and aesthetics merge.

Yet this point is also where Ginsberg expresses his most idealistic and romantic beliefs. In "Meditation and Poetics," he cites Pound's call for "direct treatment of the thing," Williams's "no ideas but in things," and the Buddhist striving for "a clear seeing attentiveness" without "intervening conceptualization" as alternatives to systems of control. In focusing on objects and responding spontaneously to their most immediately striking characteristics, the poet avoids the restraints of preconditioned thought and the mediation of those dominant sources of power which determine consciousness and mandate poetic form. That Ginsberg believes an individual can see an object outside hegemonic mediation illustrates his distance from much contemporary thought, but it also illustrates a persistent hope of people everywhere: that despite government manipulation and media conditioning, we can still find the truth.

It may be clear by now that while Ginsberg reflects what many would consider an outdated faith in romantic truth, Deliberate Prose is a book symptomatic of our postmodern condition. In his collation of Ginsberg's seemingly random snippets, rants, criticisms, and comments, Bill Morgan has constructed 
a book of wandering, disjointed being. From Ginsberg's comic suggestions on how to avoid violence with the Hell's Angels at a 1965 peace march to his touching 1992 eulogy for John Cage ("Posture erect with back and spine straight, top of the head supporting heaven"), he delivers the poet as a complex individual. That Ginsberg's writings on the other people in his life (the text's final two sections, "Writers" and "Further Appreciations") comprise nearly half the book, illustrates how writers never write alone. It is impossible to imagine Ginsberg free of Whitman's energetic yawps or Whitman without traces of Eighteenth Century American idealism.

Yet these most postmodern of the book's sections are also the weakest. Would it not be better, for example, to discover Ginsberg's blurb supporting Diane di Prima's Pieces of a Song while thumbing through di Prima? Its inclusion here seems to reflect Morgan's will toward completion rather than a desire to offer a more developed insight into Ginsberg's thought. In other words, the presence of so many pieces in the book's latter sections seems less about illuminating Ginsberg's wonderful complexity than about completing his commodification.

Still, if the reader flips through the final 225 pages of Deliberate Prose with an eye for the unique turn of phrase or historical trace, even these sections serve a valuable purpose. Reading a one paragraph obituary for Robert Duncan (1988) in which Ginsberg describes how Duncan read his entire book, The Opening of the Field, in "a corner storefront full of intimate friends mixed with a few strangers in San Francisco" at least perserves a valuable anecdote. Or maybe it merely tells us that Ginsberg was always willing to write on behalf of others, even when he had nothing to say. What we know for sure from Deliberate Prose is that Ginsberg was a writer of unquestionable passion with a strong commitment to both poetry and justice. As Ed Sanders states in the foreword, Allen Ginsberg was "a great poet, a great American, and a great friend of literature who more than any bard in history helped shape social thought and political change in his era." After reading this book, the hyperbole rings true. 